\title{
Metallurgical Failure Investigation of Cracked Steam Reformer Tubes
}

\author{
Yousuf Al-Ghadeer'1, Ali Al-Shawaf ${ }^{2}$, Abduljabbar Khan', Syed Jainulaudeen Nisthar ${ }^{1}$ \\ ${ }^{1}$ KSA Analytical, SABIC Technology Center \\ P.O. Box 11669, Jubail Industrial City 31961, Saudi Arabia \\ ghadeery@sabic.com; shawafaa@SABIC.com; \\ ${ }^{2}$ Asset Technology Center, SABIC Technology Center \\ P.O. Box 11669, Jubail Industrial City 31961, Saudi Arabia \\ KhanAJ@sabic.com; nistharsj@sabic.com
}

\section{Extended Abstract}

The outlet header of the steam reformer failed after it has been in service for about 11 years. The header cracked and forced the plant to shutdown. A field operator noticed very high skin temperature at one of the outlet header boxes. Subsequently the equipment was opened for inspection. A large circumferential crack was observed in the toe of a weld connecting an outlet header pipe to a T-piece tube. The failed samples were removed for investigation. The material of construction of the header is cast alloy $21 \mathrm{Cr} / 33 \mathrm{Ni}$ welded using Inconel filler metal 617. Metallurgical and Mechanical testing were performed on the three received samples; Tube-1, Cup-2, and Tube-3 which including visual inspection, then evaluated by using X-Ray Fluorescence, Carbon/Sulphur, and O-N-H analyser to determine the chemical composition. Then followed by metallographic examination using light microscope, and Scanning Electron Microscope (SEM) to study the defects and microstructure for sample from defect area and away from defect.

The visual inspection of the received samples shows a circumferential crack run in weld toe of tube-1 and a longitudinal crack on the weld area of tube-3. Cracks morphology are typical for creep rupture. The Analysed samples show the chemical composition of material is a typical composition as what specified in data sheet for tube- 1 and cup- 2 are GX10NiCrSiNb3220 and tube-3 is GX45NiCrSiNbTi35-25. The chemical composition of weld is slightly different which contains less Co and more Fe compared to Inconel 617. The mechanical properties; Yield Strength (YS), Ultimate Tensile Strength (UTS), and percent elongation meet the minimum requirements of manufacturer specifications for the header tubes material. An oxide layer on the outer surface of the tube indicates that it was exposed to highly elevated temperatures (flame impingement) for an extended period of time.

During Metallographic Examination and SEM analysis as in polish condition, voids were observed in the heat-affected zone in the welding area in both cracked and good samples. It was noticed that a needle shape dark phase was present in the structure of the weld toe compared to the rest of weld material, which was analysed by SEM and found to be Aluminium Nitride (AlN) particles. Voids density were more near crack however sample away from crack in similar location is also showing small voids. Those voids were located along the heat-affected zone and fusion line. Voids connect to each other and cause a crack in material and consequently a failure in the reformer tubes and plant shutdown [1][2].

Therefore, it was concluded that the failure mode is most likely localized creep damage at circumferential weld joints in the outlet header that might be assisted by dissimilar properties between weld and outlet header materials with the increase of startup/shutdown cycles. Since the integrity of header material is not affected, it was recommended to use similar weld filler materials.

\section{References}

[1] American Petroleum Institute, "Damage Mechanisms Affecting Fixed Equipment In The Refining Industry," API Recommended Practice 571, 2nd ed, April 2011.

[2] J. Parker, "Creep Cavitation in CSEF Steels," Advances in Materials Technology for Fossil Power Plants Proceedings from the Seventh International Conference, Waikoloa, Hawaii, USA, pp. 714-731, 2013. 